\title{
A reduction in errors is associated with prospectively recording them
}

\author{
Clinical article
}

\author{
Adetunji A. Oremakinde, M.B.B.S., M.Sc., ${ }^{1}$ \\ and Mark Bernstein, M.D., M.H.Sc., F.R.C.S.C. ${ }^{2,3}$

\begin{abstract}
${ }^{1}$ Department of Neurological Surgery, University College Hospital, Ibadan, Nigeria; ${ }^{2}$ Division of Neurosurgery, University of Toronto; and ${ }^{3}$ Division of Neurosurgery and Joint Center for Bioethics, Toronto Western Hospital, University Health Network, Toronto, Ontario, Canada
\end{abstract}

\begin{abstract}
Object. Error recording and monitoring is an important component of error prevention and quality assurance in the health sector given the huge impact of medical errors on the well-being of patients and the financial loss incurred by health institutions. With this in mind, assessing the effect of reporting errors should be a cause worth pursuing. The object in this study was to examine the null hypothesis that recording and publishing errors do not affect error patterns in a clinical practice.

Methods. Intraoperative errors and their characteristics were prospectively recorded between May 2000 and May 2013 in the neurosurgical practice of the senior author (M.B.). The error pattern observed between May 2000 and August 2006, which has been previously described (Group A), was compared with the error pattern observed between September 2006 and May 2013 (Group B).

Results. A total of 1108 cases in Group A and 974 cases in Group B were surgically treated. A total of 2684 errors were recorded in Group A, while 1892 errors were recorded in Group B. The ratios of cranial to spinal procedures performed in Groups A and B were 3:1 and 10:1, respectively, while the ratios of general to local anesthesia in the two groups were $2: 1$ and $1.3: 1$, respectively $(\mathrm{p}<0.0001$ for both). There was a significantly decreased proportion of cases with error ( $87 \%$ to $83 \%, \mathrm{p}<0.006)$, mean errors per case $(2.4$ to $1.9, \mathrm{p}<0.0001)$, proportion of error-related complications $(16.7 \%$ to $5.5 \%, \mathrm{p}<0.002)$, and clinical impacts of error $(2.7 \%$ to $1.0 \%, \mathrm{p}<0.0001)$ in Group B compared with Group A. Errors in Group B tended to be more preventable than those in Group A (85.8\% vs 78.5\%, p < 0.0001$)$. A significant reduction was also noticed with most types of error. A descending trend in the mean errors per case was demonstrated from the years 2001 to 2012; however, an increased severity of errors $(22.6 \%$ to 29.5\%,p < 0.0001$)$ was recorded in Group B compared with Group A.
\end{abstract}

Conclusions. Data in this study showed that the act of recording errors might alter behaviors, resulting in fewer errors. (http://thejns.org/doi/abs/10.3171/2014.5.JNS132341)

\section{KEY Words • error recording • intraoperative error • neurosurgery • prospective study}

A WARENESS of medical errors and patient safety has increased progressively in clinical practice and research over the years. Several studies have shown that medical errors are real and responsible for a large proportion of hospital adverse events. ${ }^{2,3,20,23,32}$ The Harvard Medical Practice Study, a retrospective analysis of 30,121 patient records from 51 hospitals in New York, revealed that medical errors are responsible for $58 \%$ of all hospital adverse events. ${ }^{12}$ The Institute of Medicine's report showed that medical adverse events were one of the leading causes of death in the United States and were responsible for 44,000-98,000 hospital deaths per year. ${ }^{25}$ This rate was said to have exceeded the deaths attributable to motor vehicle accidents $(43,458)$, breast cancer $(42,297)$, or AIDS $(16,516)$.

More recent studies have revealed that more than half of hospital adverse events are the result of surgical intervention and that more than half of these are deemed preventable. $16,21,26,30,31$ Many authors have demonstrated

Abbreviation used in this paper: ASA = American Society of Anesthesiologists. that most errors are the near-miss and/or inconsequential type and that this type of error can lead to serious adverse medical events if not intercepted. ${ }^{10}$ It has also been shown that most serious complications are caused by the same errors termed "near misses" in other cases. ${ }^{1}$ The near misses were inconsequential in those cases because they were intercepted either by chance or intentionally. This finding shows that preventing most near misses will, in the long run, prevent the occurrence of most serious adverse events. ${ }^{10,27,33}$

It may be important for surgeons or institutions to record and audit the incidence and nature of errors in their practice. Knowing the nature of errors in a physician's practice or an institution's setting may help to prevent more errors and contribute to quality assurance and functional efficiency. ${ }^{13,19}$ However, few studies have assessed the effect of continuous recording and evaluation of errors on the subsequent pattern of errors in surgical practices. Rebasa et al. ${ }^{28}$ assessed the influence of the continuous monitoring of adverse events on the quality of care and the incidence of errors in general surgery. They found that the incidence of adverse events remained con- 
stant but that the recorded errors decreased from $11.1 \%$ to $4.5 \%(\mathrm{p}=0.005)$ during the study period.

Stone and Bernstein ${ }^{29}$ prospectively recorded the error pattern occurring in 1108 patients who underwent elective surgery in the senior author's (M.B.) neurosurgical practice between May 2000 and August 2006. They found that $22.6 \%$ of all errors were considered major and that $77.4 \%$ were minor, with $2.7 \%$ of the errors substantially impacting the clinical course of the patient. Of all the errors, $78.5 \%$ were deemed preventable. Of the complications, $16.7 \%$ were related to errors, and $74.2 \%$ of these were declared preventable. Knowing the pattern of errors in this neurosurgeon's practice and the fact that most errors were preventable, we intended to assess whether information from error documentation affects the incidence and nature of errors. Our aim was to compare the pattern of error recorded before the published work of Stone and Bernstein ${ }^{29}$ with the pattern of errors recorded after their work to determine if recording and publishing errors over time influences the actual incidence and pattern of errors.

\section{Methods}

In this comparative observational study, we prospectively recorded the details of error (type, severity, preventability, and ensuing complications), clinical impact of errors, anesthesia details, and surgical parameters of all consecutive elective cases surgically treated by the senior author (M.B.) at the Toronto Western Hospital during the period from September 2006 to May 2013 (Group B). All urgently scheduled and/or after-hours cases were excluded. Recording was done using FileMaker Pro 8 Advance (FileMaker Inc.) as database software, in a manner similar to that used for the data (Group A) in the study by Stone and Bernstein ${ }^{29}$ in the preceding 6 years (May 2000-August 2006) in the same setting. The definitions and classifications of errors in the present study were equivalent to those applied in that previous report by Stone and Bernstein, ${ }^{29}$ as developed by the senior author (Table 1). The method of error capturing and recording was similar to the one used in Group A. Following the identification of errors by the se-

TABLE 1: Definitions of error nomenclature*

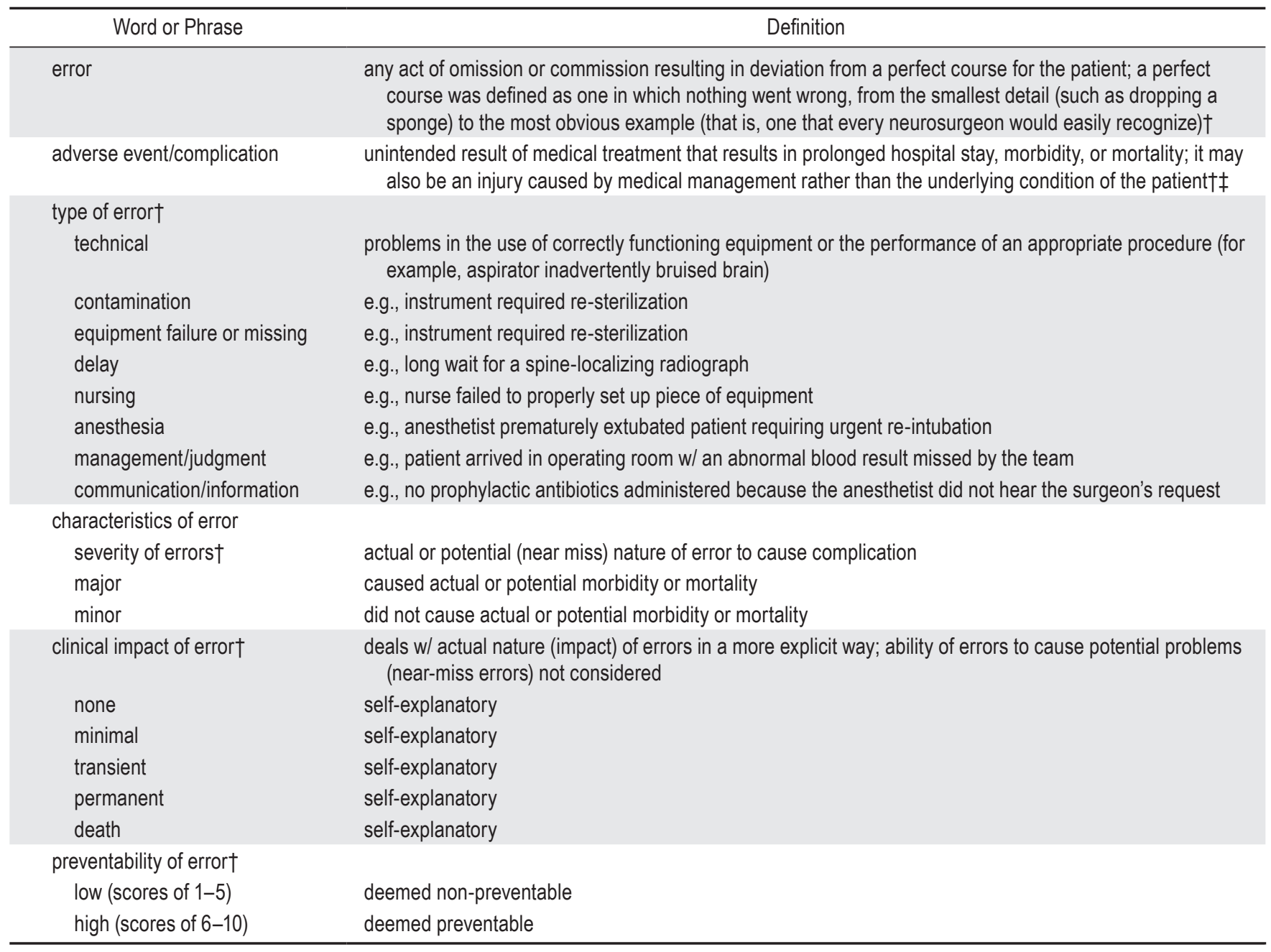

${ }^{*}$ e.g. $=$ for example.

$\dagger$ Stone and Bernstein, 2007.

$\ddagger$ Etchells et al., 2003 
nior author and other team members-which included the nurses, residents, and fellows who were present at the time the errors were committed-the errors were both rated according to the error nomenclature in Table 1 and entered into the database by the senior author immediately after every surgery. Delayed errors and/or complications were also identified and recorded in a similar manner as they occurred over time. The preoperative and intraoperative procedures in Group B were essentially the same as those in Group A, except for the introduction of the WHO checklist, which was incorporated during the Group B study period. The pattern of error recorded in Group A was compared with the pattern of error recorded in Group B. The entire period from 2000 to 2013 was also assessed to verify whether there was a continuous change in the error pattern over time. Statistical analysis was done using Microsoft Excel (Microsoft Corp.) and SPSS version 17 (SPSS Inc.), with the level of significance set at a $p$ value $<0.05$.

\section{Results}

Table 2 demonstrates the demographic characteristics of the study population. Seventeen patients were excluded from analysis because of incorrect and/or incomplete data in the database. A total of 2082 consecutive patients who had undergone elective surgical treatment between May 2000 and May 2013 were included in the present analysis. The number of patients in the two groups was comparable, with Groups A and B representing 53\% and $47 \%$ of the total population, respectively. There was a significant difference in the frequency of the types of procedures performed and the methods of anesthesia used in the two groups. The ratio of cranial to spine procedures performed in Groups A and B were 3:1 and 10:1, respectively, while the ratio of general anesthesia to local anesthesia (with or without neuroleptics) in the two groups were $2: 1$ and 1.3:1, respectively ( $p<0.0001$ for both). A

TABLE 2: Characteristics of study population*

\begin{tabular}{|c|c|c|c|}
\hline \multirow[b]{2}{*}{ Variable } & \multicolumn{2}{|c|}{ No. (\%) } & \multirow[b]{2}{*}{ p Value } \\
\hline & Group A & Group B & \\
\hline total no. of patients & 1108 & 974 & \\
\hline \multicolumn{4}{|l|}{ procedure } \\
\hline cranial & $843(76.1)$ & $875(89.8)$ & $<0.0001 \dagger$ \\
\hline spinal & $252(22.7)$ & $90(9.2)$ & \\
\hline other $\ddagger$ & $13(1.2)$ & $9(0.9)$ & \\
\hline \multicolumn{4}{|l|}{ type of anesthesia } \\
\hline general & $750(67.7)$ & $550(56.5)$ & $<0.0001 \dagger$ \\
\hline $\begin{array}{l}\text { local w/ or w/o neuro- } \\
\text { leptic (i.e., awake) }\end{array}$ & $358(32.3)$ & $414(42.5)$ & \\
\hline missing valuef & & $10(1.0)$ & \\
\hline mean ASA score $\S$ & $2.41 \pm 0.69$ & $2.82 \pm 0.59$ & $<0.0001 \rrbracket$ \\
\hline \multicolumn{4}{|c|}{$\begin{array}{l}\text { * i.e. }=\text { that is. } \\
\dagger \text { Chi-square test. } \\
\ddagger \text { "Other" and "missing value" were excluded from analysis. } \\
\S \text { Value expressed as the mean } \pm \text { standard deviation. } \\
\text { T Student's 2-tailed t-test, assuming unequal variances. }\end{array}$} \\
\hline
\end{tabular}

comparison of the mean American Society of Anesthesiologists (ASA) scores between the two study groups using independent-samples t-test analysis showed a significant difference in the tendency of patients in Group B to have higher ASA scores than those in Group A ( $p<0.0001)$. However, the tendency of patients with errors to have a higher ASA score than the patients without errors was retained in the two study groups.

The characteristics of recorded errors in the two groups are demonstrated in Tables 3 and 4, while a comparison of the study groups is graphically illustrated in Fig. 1. There was a higher proportion of cases with errors in Group A (87.1\%) than in Group B $(83.2 \%$; p < 0.006, chi-square). There was a statistically significant reduction in the mean errors per case between the two study groups

\section{TABLE 3: Pattern of errors in the two study groups}

\begin{tabular}{|c|c|c|c|}
\hline \multirow[b]{2}{*}{ Variable } & \multicolumn{2}{|c|}{ No. $(\%)$} & \multirow[b]{2}{*}{ p Value } \\
\hline & Group A & Group B & \\
\hline total no. of errors & 2684 & 1892 & \\
\hline \multicolumn{4}{|l|}{ type of error } \\
\hline technical & 747 (27.8) & $352(18.6)$ & $<0.0001^{*}$ \\
\hline contamination & $678(25.3)$ & $431(22.8)$ & $0.008^{*}$ \\
\hline $\begin{array}{l}\text { equipment failure or } \\
\text { missing }\end{array}$ & $489(18.2)$ & $538(28.4)$ & $<0.0001^{*}$ \\
\hline delay & 336 (12.5) & $335(17.7)$ & $<0.0001^{*}$ \\
\hline nursing & $152(5.7)$ & $61(3.2)$ & $<0.0001^{*}$ \\
\hline anesthesia & $119(4.4)$ & $73(3.9)$ & $0.365^{\star}$ \\
\hline management/judgment & $76(2.8)$ & $51(2.7)$ & $0.776^{*}$ \\
\hline $\begin{array}{l}\text { communication/infor- } \\
\text { mation }\end{array}$ & $51(1.9)$ & $17(0.9)$ & $0.008^{*}$ \\
\hline other & $36(1.3)$ & $34(1.8)$ & \\
\hline \multicolumn{4}{|l|}{$\begin{array}{l}\text { characteristics of error } \\
\text { severity }\end{array}$} \\
\hline major & $606(22.6)$ & $558(29.5)$ & $<0.0001^{*}$ \\
\hline minor & $2078(77.4)$ & $1329(70.2)$ & \\
\hline missing values $†$ & & $5(0.3)$ & \\
\hline \multicolumn{4}{|l|}{ clinical impactł } \\
\hline none or minimal & $1458(54.3)$ & $1024(54.1)$ & $<0.0001^{*}$ \\
\hline transient & $1155(43.0)$ & $849(44.9)$ & \\
\hline permanent & $70(2.6)$ & $19(1)$ & \\
\hline death & $2(0.1)$ & 0 & \\
\hline \multicolumn{4}{|l|}{ preventability } \\
\hline low $(1-5)$ & 578 (21.5) & $269(14.2)$ & $<0.0001^{*}$ \\
\hline high $(6-10)$ & $2106(78.5)$ & $1623(85.8)$ & \\
\hline no. of cases w/ error & $965(87.1)$ & 810 (83.2) & $<0.0001^{*}$ \\
\hline mean errors per case & $2.4 \pm 1.76$ & $1.9 \pm 1.46$ & $<0.0001 \S$ \\
\hline \multicolumn{4}{|c|}{$\begin{array}{l}\text { * Chi-square test. } \\
\dagger \text { Missing values were excluded from the analysis. } \\
\text { † "None or minimal" and "transient" were re-categorized as "low im- } \\
\text { pact," while "permanent" and "death" were re-categorized as "high im- } \\
\text { pact" before the association was subjected to the chi-square test, which } \\
\text { produced the p value quoted. } \\
\S \text { Student's 2-tailed t-test, assuming unequal variances. }\end{array}$} \\
\hline
\end{tabular}


TABLE 4: Distribution of patients and errors in each year of the study period

\begin{tabular}{ccccc}
\hline Year & $\begin{array}{c}\text { No. of } \\
\text { Patients }\end{array}$ & $\begin{array}{c}\text { No. of Patients } \\
\text { w/ Errors }\end{array}$ & $\begin{array}{c}\text { No. of } \\
\text { Errors }\end{array}$ & $\begin{array}{c}\text { Mean } \\
\text { Error }\end{array}$ \\
\hline 2000 & 128 & 94 & 226.00 & 1.7656 \\
\hline 2001 & 196 & 181 & 627.00 & 3.1990 \\
\hline 2002 & 163 & 149 & 430.00 & 2.6380 \\
\hline 2003 & 159 & 139 & 395.00 & 2.4843 \\
\hline 2004 & 182 & 166 & 433.00 & 2.3791 \\
\hline 2005 & 171 & 147 & 336.00 & 1.9649 \\
\hline 2006 & 164 & 142 & 355.00 & 2.1646 \\
\hline 2007 & 162 & 131 & 318.00 & 1.9630 \\
\hline 2008 & 151 & 140 & 328.00 & 2.1722 \\
\hline 2009 & 129 & 115 & 292.00 & 2.2636 \\
\hline 2010 & 151 & 124 & 299.00 & 1.9801 \\
\hline 2011 & 144 & 108 & 224.00 & 1.5556 \\
\hline 2012 & 134 & 106 & 236.00 & 1.7612 \\
\hline 2013 & 48 & 37 & 78.00 & 1.6250 \\
\hline
\end{tabular}

( $\mathrm{p}<0.0001,95 \%$ CI $0.618-0.823)$, as shown in Table 3 and Fig. 2.

When each type of error was compared between the two groups (Table 3 and Fig. 1), a significant reduction was noticed with technical errors $(27.8 \%$ to $18.6 \%$, p < 0.0001 ), contamination ( $25.3 \%$ to $22.8 \%, \mathrm{p}=0.008$ ), nursing errors $(5.7 \%$ to $3.2 \%, \mathrm{p}<0.0001)$, and communication/information errors $(1.9 \%$ to $0.9 \%, \mathrm{p}=0.008)$. The degree of reduction in anesthesia errors $(4.4 \%$ to $3.9 \%$, $\mathrm{p}=0.365)$ and management/judgment errors $(2.8 \%$ to $2.7 \%, p=0.776$ ) was insignificant. However, a significant increase was noticed in the proportion of errors due to equipment failure or missing equipment ( $18.2 \%$ to $28.4 \%$, $\mathrm{p}<0.0001)$ and delay (12.5\% to $17.7 \%, \mathrm{p}<0.0001)$.

The characteristics of errors were compared between the two groups as shown in Table 3 and Fig. 2. The clinical impact of errors decreased from $2.6 \%$ to $1.0 \%$ ( $p<0.0001$ ). Of the 192 complications that occurred in Group A, 31 were error related; only 8 of the 146 complications that had occurred in Group B were error related. This shows that there was a significant reduction in the proportion of errorrelated complications from $16.7 \%$ in Group A to $5.5 \%$ in Group B ( $p=0.002)$. There was a greater tendency for errors in Group B to be more preventable than those in Group $\mathrm{A}(\mathrm{p}<0.0001, \mathrm{OR}=1.669,95 \%$ CI 1.424-1.956). However, the errors recorded in Group A appeared to be significantly less severe in nature than those in Group B $(\mathrm{p}<0.0001$, $\mathrm{OR}=1.431,95 \%$ CI $1.252-1.636$ ). When the whole study period was assessed in a continuous manner, a descending trend was demonstrated for the mean errors per case from the years 2001 to 2012, as shown in Table 4 and Fig. 3.

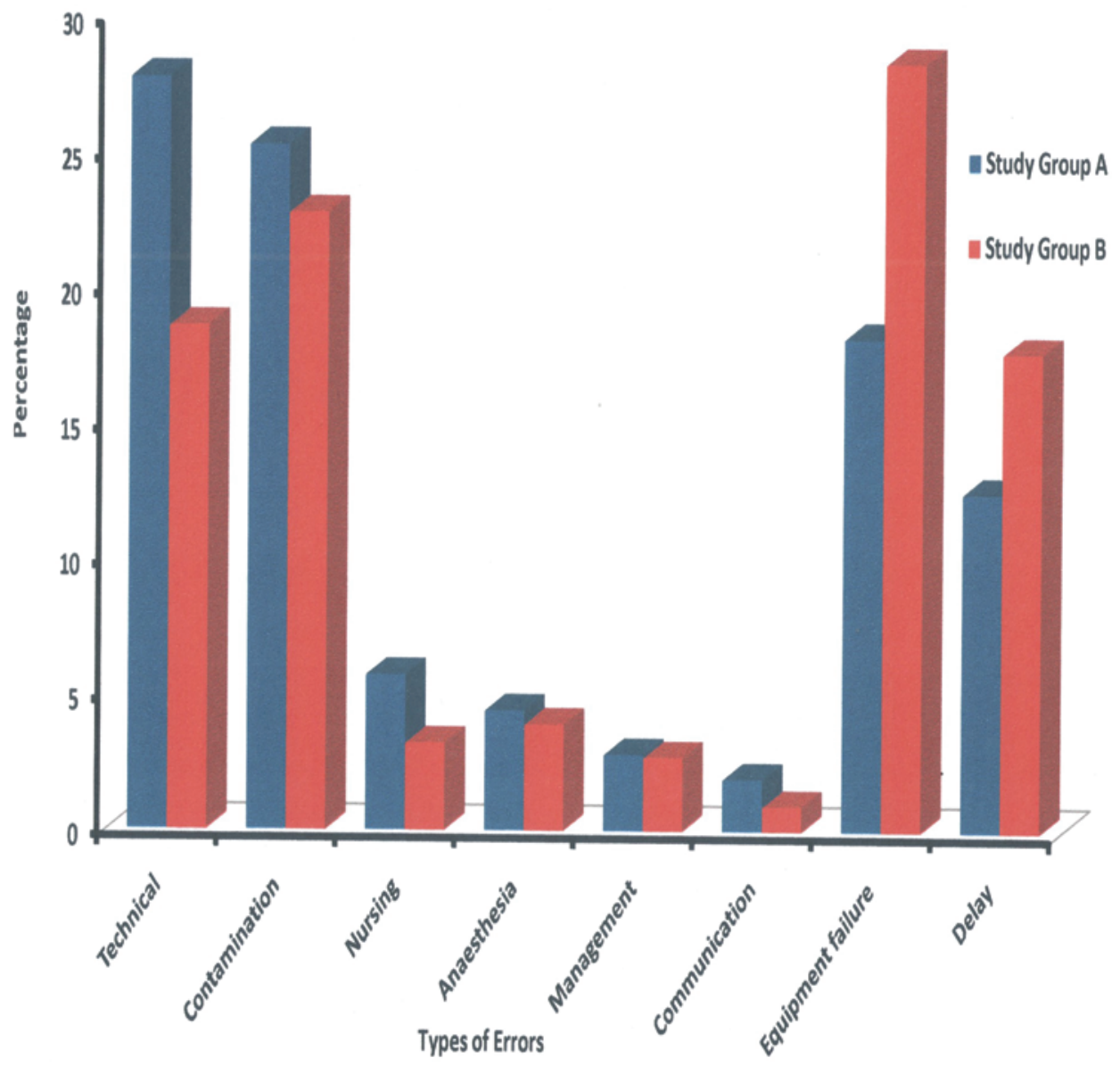

FIG. 1. Bar graph showing a comparison of error types between the two study groups. 


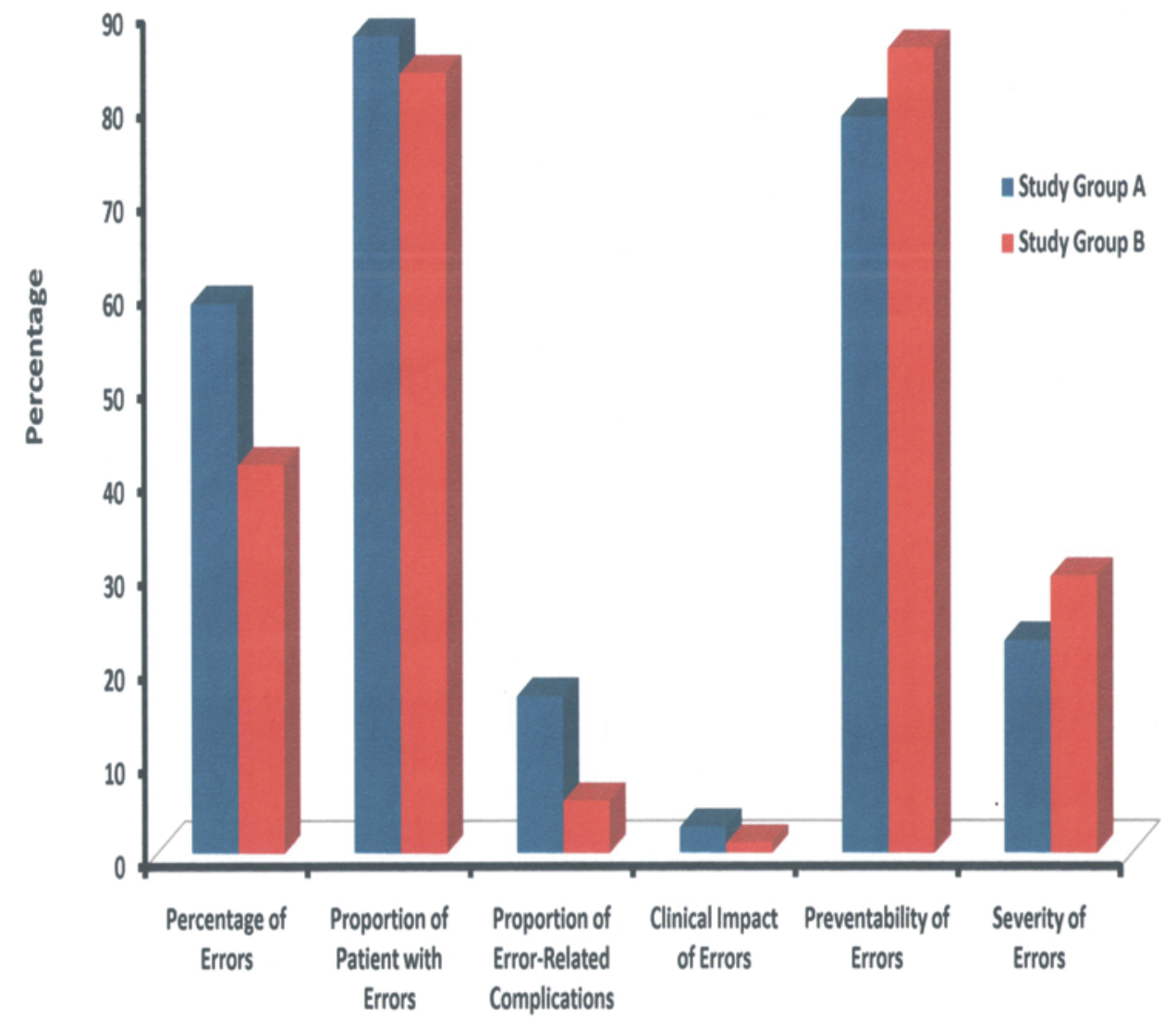

Characteristics of Errors

FIG. 2. Bar graph showing a comparison of error characteristics between the two study groups.

\section{Discussion}

Several studies, including this one and the earlier study by Stone and Bernstein, have reported that the incidence of errors and adverse events are significantly higher in patients who underwent cranial procedures than in those who underwent spine procedures and in patients with a higher ASA score than in those with a lower ASA score. ${ }^{11,29}$ However, the occurrence of errors in Group B in the present study was significantly lower than in Group A, despite the fact that there were more cranial procedures and a higher mean ASA score in Group B than in Group A. This result may mean that the higher error-prone effect of cranial procedures and cases with a high ASA score could not substantially neutralize the apparently high magnitude of error reduction demonstrated in Group B. The significant reduction in many types of error suggested that error reduction was not lopsided. The caliber of error types (technical, contamination, nursing, anesthesia, management/judgment, communication/information) that decreased suggested that most causes of errors are related to human involvement rather than institutional or nonhuman involvement, which in turn suggested that human behavioral and attitudinal changes toward error prevention may be the key factors in the error reduction observed.

This study has also revealed significant improvement in most characteristics of errors. An explanation for this improvement may be the increased awareness of errors among team members given the continuous conversations about error in this surgeon's practice and operating room. Another explanation is the enculturation of neurosurgery residents, nurses, and anesthesia staff about the commonness and preventability of errors given the outcomes of the intraoperative error monitoring done in this surgeon's practice as well as the increasing publicity about errors in both the medical arena and the lay media. These factors led team members to discuss before all surgical procedures the peculiarities of each procedure, instruments that would be needed, and errors that could be made and thus should be avoided. A third explanation is the WHO checklist, which was introduced and adopted during the Group B period. Despite the fact that other studies have reported a reduction in surgical errors since the introduction of this checklist (http://maps.cga. harvard.edu:8080/Hospital/), ${ }^{15,22}$ this instrument alone is unlikely to be responsible for the magnitude of error reduction found, because this error-reducing culture was not the only one assimilated during the Group B period. Moreover, the introduction and adoption of the WHO checklist originated from the same awareness of the commonness and preventability of errors following the appearance of publications on error recording and monitoring. Therefore, the WHO checklist is not a confounder to the Hawthorne effect of error recording on error re- 


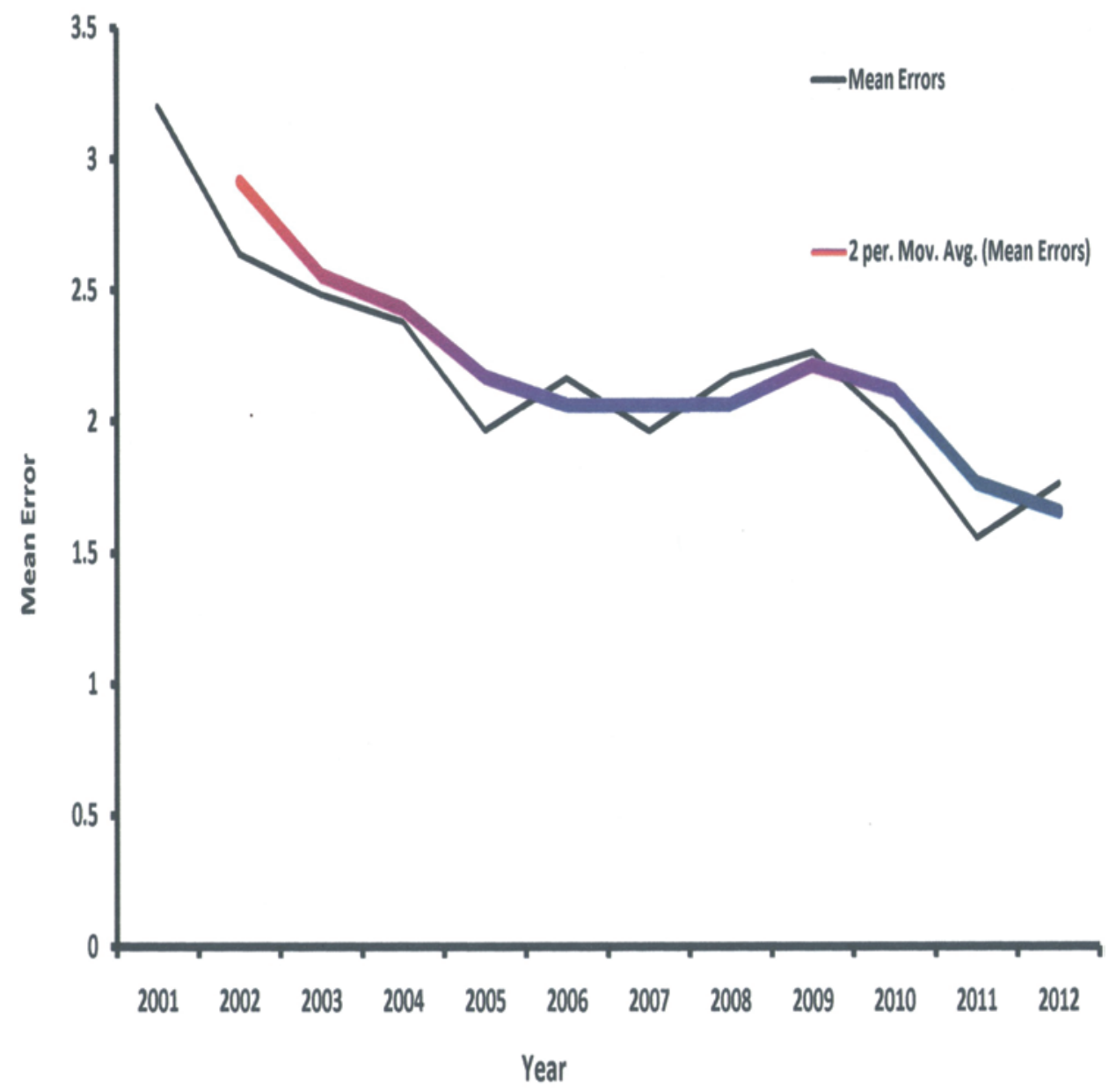

Fig. 3. Graph showing a descending trend in the mean errors per case over time from the years 2001 to 2012 . The record of errors in 2000 and 2013 were not included in this analysis to avoid bias because recording did not involve all of the months in these years, unlike other years. Black line depicts the mean error per case, while the gradient color line depicts the $2 \%$ moving average trend. 2 per.Mov.Avg. = 2\% moving average graph, which was introduced to assess the trend of the black line.

duction. Rather, its adoption and adherence is the product of the Hawthorne effect of error recording from our and other authors' previous studies. The only characteristic of error that did not decrease, but instead significantly increased, was the severity of error. This finding can be explained by the definition of a major error, which encompassed not only the errors that caused actual mortality or morbidity (errors with high clinical impact) but also errors that had the potential to cause morbidity or mortality (termed "near misses"). For the proportion of highclinical-impact errors to have significantly decreased, the component of major errors called "near misses" may have been the ones to have significantly increased and not the errors that caused actual morbidity and mortality (clinical impact). Therefore, it can be deduced that it is the impact-causing potential of the near-miss errors that was prevented from manifesting rather than the prevention of these errors. However, studies have shown that errors called near misses are common and that preventing them will, in the long run, reduce the incidence of error-related complications. ${ }^{10,27,33}$

Our study is one of the few that has assessed the effect of error recording and/or reporting on the pattern of error in medical practice in general and the first in neurosurgery in particular. Many available error studies have reported only the incidence and pattern of medical errors and adverse events. Rebasa et al., ${ }^{28}$ who performed a similar study, assessed only the change in the percentage of patients with errors over time, unlike the present study in which we assessed many variables, including the change in the number of errors per patient, proportion of patients with errors, severity of errors, preventability of errors, clinical impact of errors, complications of errors, and types of errors. The significant improvement noted in these error parameters in response to information from error reporting appears to make this study unique and versatile in providing information to health institutions yet to be convinced about the importance of error recording and reporting.

The spectrum of limitations in this study is similar to that already described in a prior report. ${ }^{29}$ There is likely to be bias given the subjectivity and limited scope of data collection and lack of standardized definitions and classifications of terminologies. The fact that one surgeon has prospectively recorded the errors in every single case can be seen as both a strength and a weakness; it suggests that 
there has been consistency in recording, but perhaps the recording criteria of the surgeon can change with time, maturity, and experience. For example, does the fact that there is a higher proportion of serious errors or errors with the potential for serious events in Group B mean that the surgeon developed "recorder fatigue;" that is, he tended to record only more serious errors as time passed. On the other hand, the surgeon's consistent interest in the area of error for a decade suggests that these data are honest and reliable. ${ }^{4-9,14,17,18,24}$ Arguably, the greatest weakness of this study is that the data were gathered from the practice of one academic neurosurgeon, in one hospital, in a socialized health care system, and thus generalizability may be an issue.

\section{Conclusions}

In this study we have shown that information from error recording can cause behavioral and attitudinal changes, which may have led to a significant reduction in the total number of errors, proportion of patients with errors, mean errors per patient, clinical impact of errors, and complications due to errors. There may be a strong cause-effect relationship between error recording and the incidence and severity of errors, and we believe that this finding may hold an important message for clinicians. We humbly suggest that personal error recording should be part of every surgeon's practice. Not only can it decrease error, but it is also an important personal audit/quality assurance for surgeons.

\section{Acknowledgments}

We thank Nathaniel Afolabi, M.Sc., for proofreading the statistical analysis and Olukemi Oremakinde, M.B.B.S., for proofreading the manuscript. We thank the residents, fellows, and nurses at Toronto Western Hospital who helped with data collection. We gratefully acknowledge the support of the Greg Wilkins-Barrick Chair in International Surgery.

\section{Disclosure}

The authors report no conflict of interest concerning the materials or methods used in this study or the findings specified in this paper.

Author contributions to the study and manuscript preparation include the following. Conception and design: Bernstein. Acquisition of data: Bernstein. Analysis and interpretation of data: Oremakinde. Drafting the article: Oremakinde. Critically revising the article: both authors. Reviewed submitted version of manuscript: both authors. Approved the final version of the manuscript on behalf of both authors: Bernstein. Statistical analysis: Oremakinde. Administrative/ technical/material support: Bernstein. Study supervision: Bernstein.

\section{References}

1. Alamgir H, Yu S, Gorman E, Ngan K, Guzman J: Near miss and minor occupational injury: does it share a common causal pathway with major injury? Am J Ind Med 52:69-75, 2009

2. Baker GR, Norton PG, Flintoft V, Blais R, Brown A, Cox J, et al: The Canadian Adverse Events Study: the incidence of adverse events among hospital patients in Canada. CMAJ 170:1678-1686, 2004

3. Bates DW, Cullen DJ, Laird N, Petersen LA, Small SD, Servi D, et al: Incidence of adverse drug events and poten- tial adverse drug events. Implications for prevention. JAMA 274:29-34, 1995

4. Bernstein M: Wrong-side surgery: systems for prevention. Can J Surg 46:144-146, 2003

5. Bernstein M, Brown B: Doctors' duty to disclose error: a deontological or Kantian ethical analysis. Can J Neurol Sci 31:169-174, 2004

6. Bernstein M, Hebert PC, Etchells E: Patient safety in neurosurgery: detection of errors, prevention of errors, and disclosure of errors. Neurosurg Q 13:125-137, 2003

7. Bernstein M, Massicotte E: Prospective error recording in surgery: a feasibility study in 500 neurosurgical cases. Evidence-Based Surg 1:57-62, 2003

8. Bernstein M, Massicotte E, Etchells E: Error in neurosurgery: a prospective pilot study. Can J Neurol Sci 28 (2 Suppl):S60, 2001

9. Bernstein M, Potvin D, Martin DK: A qualitative study of attitudes toward error in patients facing brain tumour surgery. Can J Neurol Sci 31:208-212, 2004

10. Bosma E, Veen EJ, Roukema JA: Incidence, nature and impact of error in surgery. Br J Surg 98:1654-1659, 2011

11. Boström J, Yacoub A, Schramm J: Prospective collection and analysis of error data in a neurosurgical clinic. Clin Neurol Neurosurg 112:314-319, 2010

12. Brennan TA, Leape LL, Laird NM, Hebert L, Localio AR, Lawthers AG, et al: Incidence of adverse events and negligence in hospitalized patients. Results of the Harvard Medical Practice Study I. N Engl J Med 324:370-376, 1991

13. Chassin MR, Galvin RW: The urgent need to improve health care quality. JAMA 280:1000-1005, 1998

14. Cohen FL, Mendelsohn D, Bernstein M: Wrong-site craniotomy: analysis of 35 cases and systems for prevention. Clinical article. J Neurosurg 113:461-473, 2010

15. Conley DM, Singer SJ, Edmondson L, Berry WR, Gawande AA: Effective surgical safety checklist implementation. J Am Coll Surg 212:873-879, 2011

16. Couch NP, Tilney NL, Rayner AA, Moore FD: The high cost of low-frequency events: the anatomy and economics of surgical mishaps. N Engl J Med 304:634-637, 1981

17. Etchells E, Bernstein M: Improving patient safety: just do it! Healthc Pap 2:59-65, 2001

18. Etchells E, O'Neill C, Bernstein M: Patient safety in surgery: error detection and prevention. World J Surg 27:936-942, 2003

19. Flickinger JC, Lunsford LD, Kondziolka D, Maitz A: Potential human error in setting stereotactic coordinates for radiosurgery: implications for quality assurance. Int J Radiat Oncol Biol Phys 27:397-401, 1993

20. García-Martín M, Lardelli-Claret P, Bueno-Cavanillas A, Luna-del-Castillo JD, Espigares-García M, Gálvez-Vargas R: Proportion of hospital deaths associated with adverse events. J Clin Epidemiol 50:1319-1326, 1997

21. Gawande AA, Thomas EJ, Zinner MJ, Brennan TA: The incidence and nature of surgical adverse events in Colorado and Utah in 1992. Surgery 126:66-75, 1999

22. Haynes AB, Weiser TG, Berry WR, Lipsitz SR, Breizat AH, Dellinger EP, et al: A surgical safety checklist to reduce morbidity and mortality in a global population. N Engl J Med 360:491-499, 2009

23. Hayward RA, Hofer TP: Estimating hospital deaths due to medical errors: preventability is in the eye of the reviewer. JAMA 286:415-420, 2001

24. Holliman D, Bernstein M: Patients' perception of error during craniotomy for brain tumour and their attitudes towards preoperative discussion of error: a qualitative study. Br J Neurosurg 26:326-330, 2012

25. Kohn LT, Corrigan JM, Donaldson MS (eds): Errors in health care: a leading cause of death and injury, in: To Err is Human: Building a Safer Health System. Washington, DC: National Academy Press, 2000, pp 26-48 
26. Leape LL, Brennan TA, Laird N, Lawthers AG, Localio AR, Barnes BA, et al: The nature of adverse events in hospitalized patients. Results of the Harvard Medical Practice Study II. N Engl J Med 324:377-384, 1991

27. McCafferty MH, Polk HC Jr: Addition of "near-miss" cases enhances a quality improvement conference. Arch Surg 139:216-217, 2004

28. Rebasa P, Mora L, Luna A, Montmany S, Vallverdú H, Navarro S: Continuous monitoring of adverse events: influence on the quality of care and the incidence of errors in general surgery. World J Surg 33:191-198, 2009

29. Stone S, Bernstein M: Prospective error recording in surgery: an analysis of 1108 elective neurosurgical cases. Neurosurgery 60:1075-1082, 2007

30. Thomas EJ, Studdert DM, Burstin HR, Orav EJ, Zeena T, Williams EJ, et al: Incidence and types of adverse events and negligent care in Utah and Colorado. Med Care 38:261-271, 2000

31. Thomas EJ, Studdert DM, Newhouse JP, Zbar BI, Howard
KM, Williams EJ, et al: Costs of medical injuries in Utah and Colorado. Inquiry 36:255-264, 1999

32. Vincent C, Neale G, Woloshynowych M: Adverse events in British hospitals: preliminary retrospective record review. BMJ 322:517-519, 2001 (Erratum in BMJ 322:1395, 2001)

33. Wright L, van der Schaaf T: Accident versus near miss causation: a critical review of the literature, an empirical test in the UK railway domain, and their implications for other sectors. J Hazard Mater 111:105-110, 2004

Manuscript submitted October 22, 2013

Accepted May 1, 2014.

Please include this information when citing this paper: published online June 13, 2014; DOI: 10.3171/2014.5.JNS132341.

Address correspondence to: Mark Bernstein, M.D., M.H.Sc., F.R.C.S.C., University of Toronto, Toronto Western Hospital, Division of Neurosurgery, 399 Bathurst St., 4W451, Toronto, ON M5T 2S8, Canada. email: mark.bernstein@uhn.ca. 